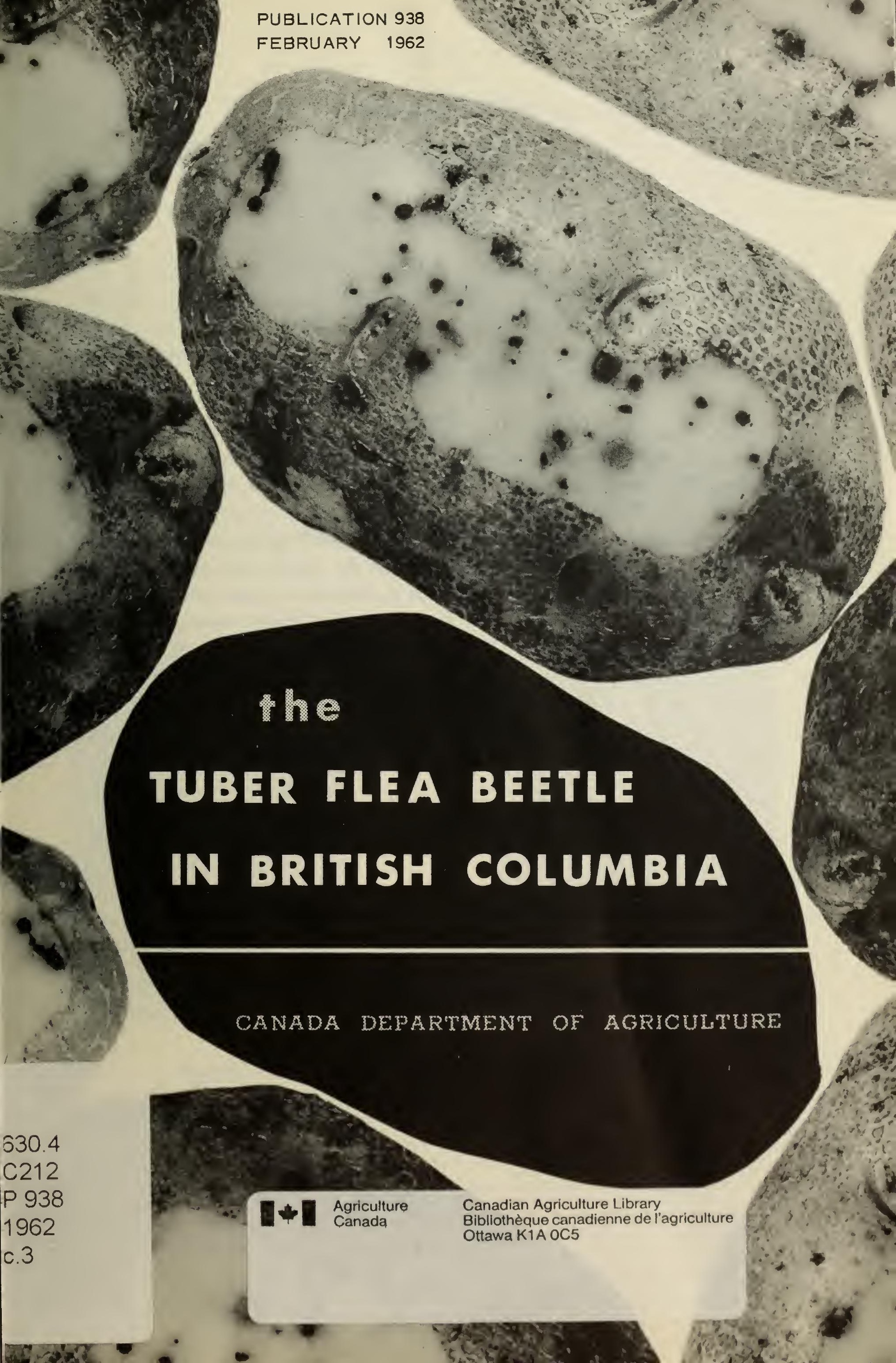




\section{PROTECT YOUR POTATOES FROM THIS BEETLE}

In Canada, the tuber flea beetle is found only in southern British Columbia, including Van couver Island. The adults are small, black, quick-moving beetles. The larvae, or worms, feed on the tubers and make fine tunnels below the skin.

You may prevent damage by killing the larvae before they attack the tubers or the adults before they lay eggs. To kill the larvae, thoroughly work one application of aldrin, dieldrin or chlordane in to the soil at planting time. To kill the adults, apply DDT or Thiodan to the plants at 10-day intervals. Thiodan also controls aphids. 


\title{
THE TUBER FLEA BEETLE \\ IN \\ BRITISH COLUMBIA
}

\author{
H.G. Fulton ${ }^{1}$ and F.L. Banham ${ }^{2}$
}

In Canada, the tuber flea beetle $\mathrm{e}^{3}$ is found only in southern British Columbia, including Vancouver Island. Potatoes heavily attacked by this pest are not marketable for table use. They are rough-looking and must be peeled deep to remove the worm tunnels.

\section{DAMAGE}

Damage is caused by the larvae, or worms, which bore in to the tubers and produce a shallow network of fine tunnels (Figure 1 , left). They form rough pimples on the surface where they enter, and cracks where their tunnels come together (Figure 1, right). Wide cracks sometimes look like common potato scab.
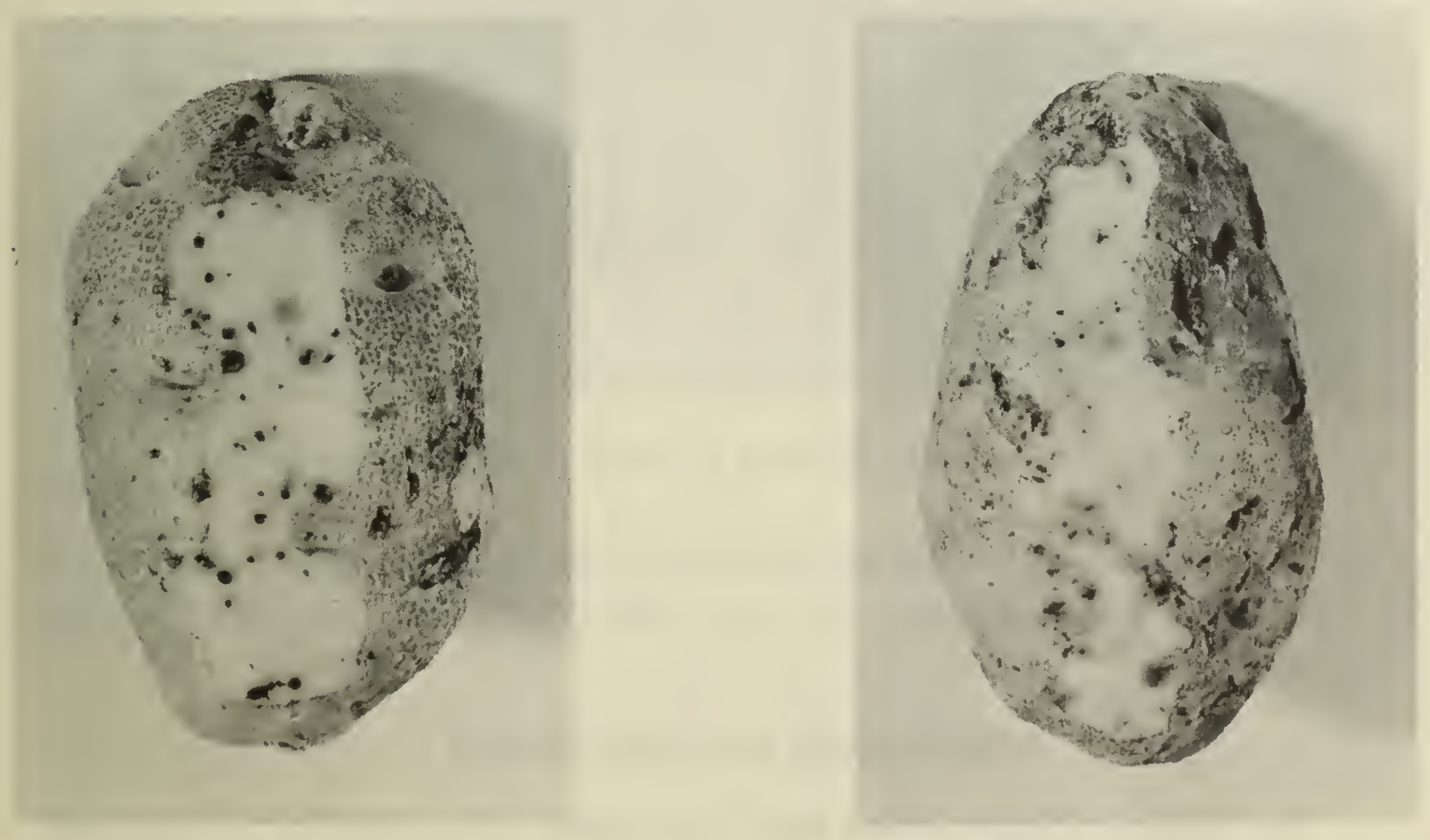

Figure 1. Potato tubers damaged by larvae of the tuber flea beetle. Left: moderate damage, showing tunnels. Right: severe damage, showing cracks like common scab where some tunnels come together.

\footnotetext{
${ }^{1}$ Entomology Substation, Chilliwack, B.C.

${ }^{2}$ Entomology Laboratory, Kamloops, B.C.

${ }^{3}$ Epitrix tuberis Gent.
} 


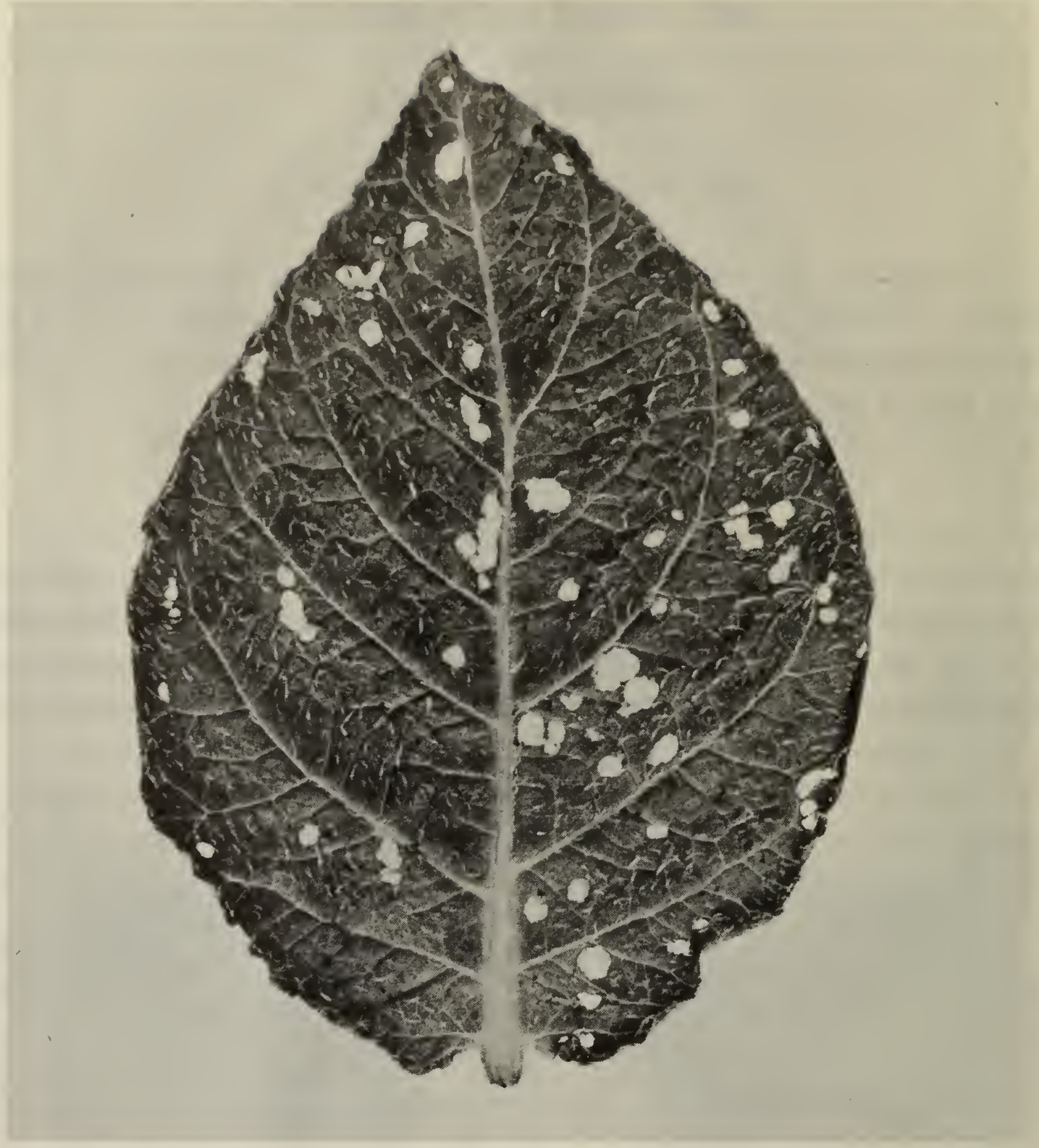

Figure 2. Potato leaflet damaged by adults of the tuber flea beetle.

The beetles feed mainly on the leaves, making small round holes (Figure 2). This injury does not reduce the crop unless the beetles are very plentiful.

\section{DESCRIPTION AND LIFE HISTORY}

The beetles (Figure 3) are black and about a sixteenth of an inch long. They jump quickly when disturbed.

The larvae are thin and uhitish and have small brown heads. When fullgrown they are half an inch long.

The beetles spend the winter in the soil. They come out from early May to late June. The females lay about 90 eggs over a period of 10 days. These are laid just below the soil surface near the bases of the potato plants. 


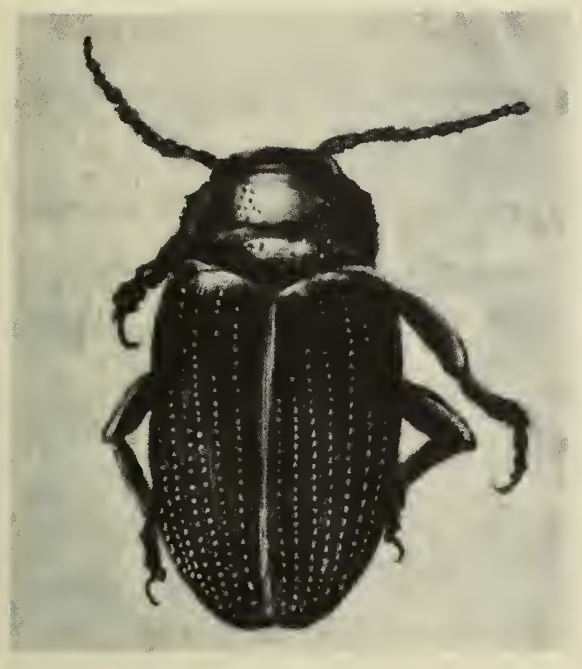

Figure 3. Adult of the tuber flea beetle.

Larvae hatch from the eggs and feed for three weeks on the root hairs and on the new tubers. When full-grown they go in to a resting, or pupal, stage in the soil. The pupae later change into beetles. There may be one or two complete generations in one year. First-generation larvae feed during June and July. If second-gen eration larvae develop they feed during August and September.

\section{HOST PLANTS AND SPREAD}

The beetles can fly long distances when seeking host plants. They feed almost entirely on potato and tomato or other plants of this family. In the spring and fall, if potato leaves are not available they may feed on such plants as beans, cucumbers, chard, lettuce, cabbage, Canada thistle, or chickweed.

Damaged potatoes do not spread this pest. You may safely use them as seed, because the larvae leave the tubers as soon as they are dug.

\section{CONTROL}

Dig early crops of potatoes as soon as possible. Infestations cannot be reduced by planting at a distance from last year's field.

Certain insecticides applied either to the foliage or to the soil will control this pest. Foliage treatments kill the adult beetles before they have laid eggs and soil treatments kill the larvae before they have attacked the tubers.

\section{Main-crop Potatoes}

Soil treatment. - To kill the larvae, apply aldrin, dieldrin, or chlordane and thoroughly work it in to the soil.

Make a good seedbed; then apply the insecticide evenly on the surface and at once work it about four inches in to the soil by harrowing, disking or rotary-tilling. If it is more convenient, apply the insecticide after planting or after the first sprouts have come up. Use on ef the following:

\section{Ins ecticide}

Aldrin, $\quad 2.5 \%$ dust

$20 \%$ emulsifiable concentrate

Dieldrin, $1.5 \%$ dust

$20 \%$ emulsifiable concentrate

Chlordane, $5 \%$ dust

$65.5 \%$ emulsifiable concentrate

\section{Amount per acre}

\section{0 pounds}

2 gallons

100 pounds

$3 / 4$ gallon

150 pounds

1 gallon 
Use the emulsifiable concentrate in enough water to cover the area evenly.

'Thorough and quick incorporation is very important for proper control. One treatment will last for at least one season.

If you grow potatoes on the same soil the next year, you may not need as much insecticide. Especially on light soils that have not been often or deeply cul tivated, you need apply only a quarter to half as much. On muck or heavy clay soils, which need deep cultivation, apply the full rate each year.

Soil treatments do not control late blight or aphids.

Foliage treatment. - To kill the beetles, start when two thirds of the plants have come up, and put on insecticide every 10 days until August 20, or until the plants die or are killed. As many as seven or eight applications may be needed.

Use one of the following:

Insecticide

Amount per acre

DDT, $50 \%$ wettable powder

2 pounds

$5 \%$ dust

35 to 50 pounds

Thiodan, $2 \mathrm{E}$ emulsifiable concentrate

1 to 2 quarts

$3 \%$ dust 30 to 50 pounds

Use the higher amount if the foliage is dense. Apply the wettable powder or emulsifiable concentrate in 100 to 200 gallons of water per acre, depending on top growth.

Late blight is a problem at the coast in wet years. When the rish of late blight is high, a fungicide may be included with the insecticide. This is usually not necessary in the interior.

1. For sprays use fixed copper or zineb according to the manufacturer's directions.

2 For dusts use $7 \%$ copper-lime or fixed copper dust.

NOTE: Thiodan, if properly applied, also controls aphids. See the following publications of the British Columbia Department of Agriculture: "Control Potato Leaf Roll", En tomologi cal Circular 16; and "Potato Sprayers", Bulletin A.E. 10.

\section{Early-crop Potatoes}

Potatoes planted in March or April and dug in July are attacked by a single generation of the beetles. Two applications of DDT or Thiodan to the tops will give good control. Make the first between June 1 and 7 , the second about 10 days later. It is cheaper to treat the foliage than the soil when only two applications are needed. Proper timing of the applications is essential. 


\section{Cautions}

Follow closely all the cautions listed on the label of the insecticide container, especially those for the use of Thiodan.

\section{MORE INFORMATION}

For more information, inquire at the nearest research station of the Canada Department of Agriculture: 6660 N.W. Marine Drive, Vancouver; Post Office Building, Chilliwack; or Box 210, Kamloops. Or write the Provincial Entomologist, Douglas Building, Victoria, or Court House, Vernon.

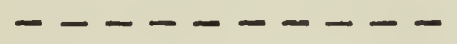

Some brand names are used in this publication because the chemical names are difficult for general use and there are no official common names for the active ingredients. 
First printed..... April 1955

Reprinted ...... August 1955

Revised...... February 1962

Copies of this publication may be obtained from:

Information Division

CANADA DEPARTMENT OF AGRICULTURE

Ottawa, Ontario

ROGER DUHAMEL, F.R.S.C 